\title{
Towards a merged satellite and in situ fluorescence ocean chlorophyll product
}

\author{
H. Lavigne ${ }^{1,2}$, F. D'Ortenzio ${ }^{1,2}$, H. Claustre ${ }^{1,2}$, and A. Poteau ${ }^{1,2}$ \\ ${ }^{1}$ Laboratoire d'Océanographie de Villefranche, CNRS, UMR7093, 06230 Villefranche-sur-Mer, France \\ ${ }^{2}$ Université Pierre et Marie Curie-Paris 6, UMR7093, Laboratoire d'Océanographie de Villefranche, 06230 \\ Villefranche-sur-Mer, France
}

Correspondence to: H. Lavigne (heloise.lavigne@obs-vlfr.fr)

Received: 2 November 2011 - Published in Biogeosciences Discuss.: 13 December 2011

Revised: 3 May 2012 - Accepted: 3 May 2012 - Published: 12 June 2012

\begin{abstract}
Understanding the ocean carbon cycle requires a precise assessment of phytoplankton biomass in the oceans. In terms of numbers of observations, satellite data represent the largest available data set. However, as they are limited to surface waters, they have to be merged with in situ observations. Amongst the in situ data, fluorescence profiles constitute the greatest data set available, because fluorometers have operated routinely on oceanographic cruises since the 1970s. Nevertheless, fluorescence is only a proxy of the total chlorophyll $a$ concentration and a data calibration is required. Calibration issues are, however, sources of uncertainty, and they have prevented a systematic and wide range exploitation of the fluorescence data set. In particular, very few attempts to standardize the fluorescence databases have been made. Consequently, merged estimations with other data sources (e.g. satellite) are lacking.

We propose a merging method to fill this gap. It consists firstly in adjusting the fluorescence profile to impose a zero chlorophyll $a$ concentration at depth. Secondly, each point of the fluorescence profile is then multiplied by a correction coefficient, which forces the chlorophyll $a$ integrated content measured on the fluorescence profile to be consistent with the concomitant ocean colour observation. The method is close to the approach proposed by Boss et al. (2008) to correct fluorescence data of a profiling float, although important differences do exist. To develop and test our approach, in situ data from three open ocean stations (BATS, HOT and DYFAMED) were used. Comparison of the socalled "satellite-corrected" fluorescence profiles with concomitant bottle-derived estimations of chlorophyll $a$ concentration was performed to evaluate the final error (estimated at
\end{abstract}

$31 \%$ ). Comparison with the Boss et al. (2008) method, using a subset of the DYFAMED data set, demonstrated that the methods have similar accuracy. The method was applied to two different data sets to demonstrate its utility. Using fluorescence profiles at BATS, we show that the integration of "satellite-corrected" fluorescence profiles in chlorophyll $a$ climatologies could improve both the statistical relevance of chlorophyll $a$ averages and the vertical structure of the chlorophyll $a$ field. We also show that our method could be efficiently used to process, within near-real time, profiles obtained by a fluorometer deployed on autonomous platforms, in our case a bio-optical profiling float. The application of the proposed method should provide a first step towards the generation of a merged satellite/fluorescence chlorophyll $a$ product, as the "satellite-corrected" profiles should then be consistent with satellite observations. Improved climatologies with more consistent satellite and in situ data are likely to enhance the performance of present biogeochemical models.

\section{Introduction}

In the ocean, chlorophyll $a$ concentration (the sum of chlorophyll $a(\mathrm{Chl} a$ ), divinyl chlorophyll $a$ and chlorophyllide $a$ ) is considered a good, although not optimal, proxy for phytoplankton biomass (e.g. Cullen, 1982; Strickland, 1965). Considering the key role of phytoplankton in the global carbon cycle, understanding the $\mathrm{Chl} a$ concentration ("Chl $a$ ") spatio-temporal distribution and variability is of primary importance for modern oceanography (Claustre et al., 2010). 
Although it is the most abundant biological oceanic measurement, $\mathrm{Chl} a^{\mathrm{C}}$ observations are, however, scarce, particularly in comparison with the number of physical observations available (e.g. temperature and salinity). Among the three main approaches that exist for measuring $\mathrm{Chl} a^{\mathrm{C}}$ (i.e. water sampling, ocean colour and induced fluorescence; see later), fluorescence is the only one that has not been included in global re-analysis, as, for example, open ocean climatologies of Chl $a^{\mathrm{C}}$ (Gregg and Conkright, 2001). However, it represents the most important source of in situ data in terms of numbers of observations (i.e. 36707 profiles in the World Ocean Database 2009; Boyer et al., 2009), and this trend is likely to increase in the near future given the recent development of autonomous platforms equipped with fluorometers. Combining fluorescence profiles with other data (i.e. ocean colour and sampling bottles) should strongly enhance our knowledge of the spatio-temporal variability of the $\mathrm{Chl} a^{\mathrm{C}}$, and consequently, improve our understanding of the phytoplankton dynamics.

The conventional and historical approach to measure $\mathrm{Chl} a^{\mathrm{C}}$ in the ocean is to filter water samples collected at different depths, which are further analysed using three principal benchtop methods: fluorometry (Holm-Hansen et al., 1965), spectrophotometry (Lorenzen, 1967) and chromatography (Mantoura and Llewellyn, 1983). The three techniques have different accuracy and precision. A general consensus indicates that the most accurate method is high performance liquid chromatography (HPLC, Gieskes and Kraay, 1983; Hooker et al., 2009), which provides the concentrations of a large spectrum of phytoplankton accessory pigments in addition to $\mathrm{Chl} a^{\mathrm{C}}$.

There are also bio-optical techniques that offer alternative methods to obtain $\mathrm{Chl} a^{\mathrm{C}}$ in the ocean. The peak of particulate absorption between $650 \mathrm{~nm}$ and $715 \mathrm{~nm}$ is a signature of Chl $a$ absorption and can be used to derive $\mathrm{Chl} a^{\mathrm{C}}$ (Davis et al., 1997; Boss et al., 2007). Absorption of particulates is obtained from in-situ total absorption measurements corrected for pure water and coloured dissolved material absorption. Moreover, empirical relationships, relating the gradients in light field to in-water compounds, were developed to estimate $\mathrm{Chl} a^{\mathrm{C}}$ from radiometers that measure light intensity in the visible spectrum (Morel, 1988). Similarly, bio-optical relationships were successfully developed to obtain $\mathrm{Chl} a^{\mathrm{C}}$ from satellite-mounted radiometers. The satellite-derived maps provide a unique temporal and spatial picture of the $\mathrm{Chl} a^{\mathrm{C}}$ at global scale (Feldman et al., 1989; McClain et al., 1998). However, satellite observations are limited to the ocean surface and their error on $\mathrm{Chl} a^{\mathrm{C}}$, calculated by match-up analysis of concurrent satellite and HPLC measurements, was evaluated to vary around $\pm 35 \%$ in the open ocean (Bailey and Werdell, 2006; Moore et al., 2009).

Bio-optical approaches based on fluorescence techniques (Lorenzen, 1966) provide another method to evaluate Chl $a^{\mathrm{C}}$. Irradiated by blue light, Chl $a$ absorbs and re-emits, in the red part of the spectrum, a quantity of light that is proportional to $a^{*} \cdot \mathrm{Chl} a^{\mathrm{C}}$, where $a^{*}$ is the chlorophyll-specific absorption coefficient. Based on this concept, instruments inducing and measuring fluorescence (i.e. fluorometers) provide a robust method to estimate in situ $\mathrm{Chl} a^{\mathrm{C}}$ with a non-invasive technique. Additionally, the acquisition frequency of fluorometers (up to $8 \mathrm{~Hz}$ ), and their possible connection with a CTD probe, allows for winch-based deployment and the collection of vertically continuous profiles of fluorescence. Although calibration issues still prevent a wide scientific exploitation of fluorescence profiles (see later), during the last $30 \mathrm{yr}$ they have been extensively collected, becoming a standard measurement in oceanography.

The calibration of fluorometers is a complex process. Manufacturer calibration is often too simplistic to meet scientific requirements, and calibration needs to be regularly verified, due to lamp and sensor performance degradation with time. However, the most problematic issues are the high variability and nonlinearity of the fluorescence/Chl $a^{\mathrm{C}}$ relationship (Falkowski and Kiefer, 1985; Kiefer, 1973). Changes in environmental conditions (e.g. light intensity, nutrient availability) can induce modifications in taxonomic assemblages or in physiological states of phytoplankton, with an impact on the fluorescence to $\mathrm{Chl} a^{\mathrm{C}}$ ratio (Cullen, 1982; Althuis et al., 1994; Claustre et al., 1999; Cleveland and Perry, 1987; Loftus and Seliger, 1975). As mentioned above, fluorescence is not directly proportional to $\mathrm{Chl} a^{\mathrm{C}}$ but to $a^{*} \cdot \mathrm{Chl} a^{\mathrm{C}}$. Yet, $a^{*}$ strongly varies, especially because of the packaging effect, which induces a decrease in $a^{*}$ in response to an increase in the size of the phytoplankton cell and/or an increase in the $\mathrm{Chl} a^{\mathrm{C}}$ content per cell (Morel and Bricaud, 1981). Consequently, $a^{*}$ changes with the community composition and with the light intensity, which decreases with depth. Another source of variability for the fluorescence to $\mathrm{Chl} a^{\mathrm{C}}$ ratio is the non-photochemical quenching (NPQ) of fluorescence, particularly relevant in the surface layers. NPQ occurs when, in response to supra-optimal light irradiation, phytoplankton triggers photo-protection mechanisms, inducing a drastic decrease of the fluorescence to $\mathrm{Chl} a^{\mathrm{C}}$ ratio (Kolber and Falkowski, 1993; Müller et al., 2001). The final effect of NPQ is a decrease of fluorescence at the surface, not paralleled by a Chl $a^{\mathrm{C}}$ diminution (Xing et al., 2011; Sackman et al., 2008; Cullen and Lewis, 1995). An in situ calibration of the fluorometers is generally carried out at the time of deployment, using Chl $a^{\mathrm{C}}$ obtained from water samples collected during the fluorescence profiles acquisition and further analyzed with HPLC or spectrofluorometer (Cetinic et al., 2009; Sharples et al., 2001; Strass, 1990). This operation, however, is not systematically carried out. Moreover, even when bottle data are available, they are often recorded in a different database to the fluorescence profiles. During oceanographic cruises, in situ fluorescence profiles are generally used to indicate a "generalized" biomass index (Strickland, 1968) and then interpreted to decide the depths for bottle sampling. Occasionally, they are used to improve the 
interpolation between discrete $\mathrm{Chl} a^{\mathrm{C}}$ estimations (see, for example, Morel and Maritorena, 2001). However, extensive and global analyses, including several data sets of fluorescence profiles, obtained by different fluorometers, are lacking.

The main consequence of this situation is that fluorescence data are underused. The constraints of calibration hinder any combination of the different fluorescence data sets and also prevent their merging with other data sources. No fluorescence profile has been integrated, for example, in existing $\mathrm{Chl} a^{\mathrm{C}}$ climatologies (Conkright et al., 2002), which are exclusively based on $\mathrm{Chl} a^{\mathrm{C}}$ estimations obtained from water sample data (HPLC or spectrofluorometer measurements). Consequently, climatologies are strongly interpolated, as the initial data density is generally low (Conkright et al., 2002). Furthermore, existing methods to generate blended $\mathrm{Chl} a^{\mathrm{C}}$ products combining data derived from different methods generally exclude fluorescence data. They have been limited to the merging of ocean colour satellite observations with water sample-derived estimations. A pure blending method (Gregg and Conkright, 2001) was developed to directly merge satellite and in situ data. A more indirect approach used satellite and in situ data to establish empirical relationships between the surface $\mathrm{Chl} a^{\mathrm{C}}$ and its vertical signature (Morel and Berthon, 1989; Uitz et al., 2006), in order to reconstruct a vertical profile for each available satellite pixel. Surprisingly, no attempt yet has been made to merge fluorescence profiles with alternative $\mathrm{Chl} a^{\mathrm{C}}$ measurement approaches.

In summary, the lack of standardization of the fluorescence calibration methods prevents the development of a merged procedure that makes use of a number of different fluorescence data sets and of their combination with other data sources.

Recent approaches were presented, based on ancillary data (e.g. simultaneous irradiance profiles, Xing et al., 2011), on the shape of fluorescence profile (Mignot et al., 2011) or on satellite ocean colour Chl $a^{\mathrm{C}}$ observations (Boss et al., 2008). The last method (Boss et al., 2008), although developed to correct a profiling float fluorometer, also points to a reliable way to merge fluorescence profiles and satellite observations. However, the Boss et al. (2008) approach, in its present form, was developed to be applied to a time series of profiles performed by a single fluorometer deployed on a profiling float and is likely not suitable for other data sets. Indeed, a unique set of correction factors was calculated for the whole lifetime of the profiling float. Consequently, although the re-adjusted data are generally consistent with the satellite, the computation of a unique set of correction factors implies that some profiles could be erroneously corrected. In the framework of a combined satellite-fluorescence profile product, the present form of the Boss et al. (2008) method could then be modified in order to be applied on a single profile basis.

Here, we propose a method to merge fluorescence profiles and satellite ocean colour observations, which is conceptu- ally close to the Boss et al. (2008) procedure. The main difference is that it is applicable on a single profile basis. Consequently, each profile will be characterized by a specific set of correction factors and the obtained $\mathrm{Chl} a^{\mathrm{C}}$ profiles would be strictly consistent with the satellite estimation measured in the same place and at the same time.

We developed and tested the merging method on three long-term time series of simultaneous observations of fluorescence profiles and $\mathrm{Chl} a^{\mathrm{C}}$ obtained from HPLC analysis. Fluorescence profiles and satellite data were matched and combined to generate $\mathrm{Chl} a^{\mathrm{C}}$ profiles. Finally, the obtained profiles were compared with concomitant HPLC Chl $a^{\mathrm{C}}$, to test the method performances. Additionally, performance indexes of the present merging method were compared to the Boss et al. (2008) method performances on a subset of DYFAMED data. The different sources of error influencing the accuracy of the merged profiles were then discussed. Finally, two examples of application were presented: the production of a monthly $\mathrm{Chl} a^{\mathrm{C}}$ climatology using fluorescence profiles and the treatment of a time series of fluorescence profiles recorded by a fluorometer deployed on a profiling float. The two applications demonstrate the capacity of the method to enhance the consistency of the fluorescence data set with other Chl $a^{\mathrm{C}}$ data sources available. Consequently, they represent a first step towards merged $\mathrm{Chl} a^{\mathrm{C}}$ estimations.

\section{Data}

In situ data from the long-term time series data sets of stations BATS (Michaels and Knap, 1996, in the Sargasso Sea), DYFAMED (Marty et al., 2002, in the northwestern Mediterranean Sea) and HOT (Karl and Lukas, 1996, in the North Pacific) were used over the 1998-2007 period (i.e. the period of activity of the SeaWiFS ocean colour sensor). For each station, fluorescence, temperature and salinity profiles were extracted, as well as HPLC $\mathrm{Chl} a^{\mathrm{C}}$ derived from discrete samples, when available.

Surface $\mathrm{Chl} a^{\mathrm{C}}$ over the three sites was derived from the 8-day images at $9 \mathrm{~km}$ spatial resolution from the SeaWiFS satellite ocean colour sensor, which constitutes the longest temporal series of ocean colour observations (McClain, 2009). For each available fluorescence profile, the satellite image that matched the date of the profile was selected, and a Chl $a^{\mathrm{C}}$ average was calculated in a $\pm 0.1^{\circ}$ by $\pm 0.1^{\circ}$ sized box centred on the profile geographical position (i.e. "fluo" match-up). A "fluo" match-up was retained, if more than $30 \%$ of pixels were available in the box.

For each station, an additional satellite match-up analysis was performed by extracting ocean colour data when HPLC observations were available ("HPLC" match-up). To verify the sensitivity of the match-up analysis to the size of the temporal and spatial windows, near surface $\mathrm{Chl} a^{\mathrm{C}}$ from HPLC profiles (computed as described in Morel and Berthon, 1989) was compared to satellite observations extracted from 
SeaWiFS images at both 8-day and 1-day temporal resolution and on spatial boxes of $\pm 0.25^{\circ}$ and $\pm 0.1^{\circ}$ dimensions (Table 1). Increasing temporal and spatial resolutions does not significantly modify the similarity between the HPLC and satellite estimations (tests of similarity on absolute percent difference: 8 -day $\pm 0.25^{\circ}$ with 8 -day $\pm 0.1^{\circ}$ p-value $=$ 0.86 ; 8 -day $\pm 0.25^{\circ}$ with 1 -day $\pm 0.25^{\circ} \mathrm{p}$-value $=0.66$ ). However, the number of match-ups strongly decreased. Based on these tests, carried out on the "HPLC" match-ups, the "fluo" match-up procedure was then performed using the 8-day resolution products and the $\pm 0.1^{\circ}$ square boxes.

In the BATS and DYFAMED HPLC data sets, the lowest Chl $a^{\mathrm{C}}$ was around $0.001 \mathrm{mg} \mathrm{m}^{-3}$, whereas at the HOT station lowest concentrations were about $0.01 \mathrm{mg} \mathrm{m}^{-3}$. As observations showed that, in the most oligotrophic regions of the global ocean, $\mathrm{Chl} a^{\mathrm{C}}$ at the surface is about $0.02 \mathrm{mg} \mathrm{m}^{-3}$ (Ras et al., 2008), very low $\mathrm{Chl} a^{\mathrm{C}}\left(<0.01 \mathrm{mg} \mathrm{m}^{-3}\right)$ should correspond to deep measurements that are not relevant to this present study. Consequently, to standardize the data sets, we eliminated all the HPLC measurements $<0.01 \mathrm{mg} \mathrm{m}^{-3}$.

On the HPLC profiles, negative spikes ( $2 \%$ of total HPLC data points) and incomplete profiles (i.e. less than 5 points, $2.2 \%$ of available profiles) were also removed. An additional quality control procedure (D’Ortenzio et al., 2010) was applied to the fluorescence profiles, which checked for outliers, spikes and unexpected gradients. Finally, an additional visual control allowed for the identification of altered profiles, which were removed.

After this processing, the fluorescence database was composed of 3614 profiles, all with an associated satellite ocean colour Chl $a^{\mathrm{C}}$ estimation: 91 at DYFAMED, 1560 at HOT, 1963 at BATS (see Table 2 for a summary of the available data).

\section{Method}

\subsection{Overview}

The common procedure to convert a fluorescence profile (FLUO) into Chl $a^{\mathrm{C}}$ (Boss et al., 2008; Cetinic et al., 2009; Xing et al., 2011) can be formalised by

$\mathrm{Chl} a^{\mathrm{C}}=\alpha(\mathrm{FLUO}-\beta)$.

The $\beta$ parameter indicates the response of the instrument in the absence of signal, and it is commonly computed by blocking the sensor window. The $\alpha$ coefficient is initially provided by the manufacturer, and it is calculated by linear regression with samples at fixed and known $\mathrm{Chl} a \mathrm{C}$. Postprocessing evaluation of the $\alpha$ parameter can be carried out by regressing fluorescence profiles with in situ $\mathrm{Chl} a^{\mathrm{C}}$ obtained by HPLC or fluorometric water sample analyses. The post-processing adjustment is generally more accurate than the manufacturer calibration, as it is often carried out in natural conditions and on a greater number of data points. How-
Table 1. Sensitivity study on the impact of the resolution of the satellite extraction window of "HPLC" match-up. The number $(N)$ and the percentage of valid match-ups, the median percent difference (MPD) between satellite and in-situ data as well as the determination coefficient $\left(r^{2}\right)$ of the regression performed between two data sets are reported.

\begin{tabular}{lrrrrr}
\hline $\begin{array}{l}\text { Temporal } \\
\text { resolution }\end{array}$ & $\begin{array}{r}\text { Spatial } \\
\text { resolution }\end{array}$ & $\begin{array}{r}\text { Percentage of } \\
\text { valid match-ups }\end{array}$ & MPD & $r^{2}$ & $N$ \\
\hline 8 days & $\pm 0.25^{\circ}$ & $80.5 \%$ & $32 \%$ & 0.62 & 267 \\
8 days & $\pm 0.1^{\circ}$ & $77.5 \%$ & $34 \%$ & 0.63 & 256 \\
1 day & $\pm 0.25^{\circ}$ & $18.5 \%$ & $36 \%$ & 0.43 & 56 \\
\hline
\end{tabular}

Table 2. Quantity of fluorescence profiles available after each step of the data processing.

\begin{tabular}{lrrr}
\hline & DYFAMED & BATS & HOT \\
\hline Raw data downloaded & 184 & 2411 & 1912 \\
Satellite matchup & 98 & 2027 & 1581 \\
Quality control & 91 & 1963 & 1560 \\
HPLC matchup & 54 & 105 & 102 \\
\hline
\end{tabular}

ever, it requires the analysis of water samples, which are not always available.

Here, we evaluated the $\beta$ parameter by considering fluorescence measurements at depth, where $\mathrm{Chl} a^{\mathrm{C}}$ is supposed to be zero, whereas the $\alpha$ parameter was estimated for each fluorescence profile from a simultaneous ocean colour observation.

The evaluation of the $\alpha$ parameter was based on the assumption that the near-surface $\mathrm{Chl} a^{\mathrm{C}}, \mathrm{chl}_{\text {surf }} \mathrm{C}^{\mathrm{C}}$ in $\mathrm{mg} \mathrm{m}^{-3}$, and the integrated $\mathrm{Chl} a$ biomass across $k$ times the euphotic depth $\langle\mathrm{chl}\rangle_{k \cdot Z_{\mathrm{e}}}$ in $\mathrm{mg} \mathrm{m}^{-2},(k=1$ or $k=1.5)$ are related (Eq. 2; Morel and Berthon, 1989; Uitz et al., 2006). The euphotic depth is defined as the depth at which light intensity falls to $1 \%$ of its value at the surface.

$\langle\operatorname{chl}\rangle_{k \cdot Z e}=A \operatorname{chl}_{\text {surf }} \mathrm{C}^{B}$

In Eq. (2), $A$, expressed in meters, and $B$, dimensionless, are coefficients that were determined by regressions carried out on in situ data (Uitz et al., 2006). They have different values depending on whether the water column is stratified or not.

\subsection{Parameters computation}

Following Morel and Berthon (1989) and Uitz et al. (2006), the discrimination between a stratified or mixed water column was determined according to the ratio between the depth of the euphotic layer $\left(Z_{\mathrm{e}}\right)$ and the depth of the mixed layer $\left(Z_{\mathrm{m}}\right)$. The water column was assumed to be mixed when $Z_{\mathrm{e}} / Z_{\mathrm{m}}<1$ and stratified when $Z_{\mathrm{e}} / Z_{\mathrm{m}}>1 . Z_{\mathrm{m}}$ was evaluated from potential density profiles using a density criterion of $0.03 \mathrm{~kg} \mathrm{~m}^{-3}$ (de Boyer Montegut et al., 2004; D’Ortenzio 
et al., 2005). $Z_{\mathrm{e}}$ was determined with the following procedure: (1) the attenuation coefficient at $490 \mathrm{~nm}, K_{\mathrm{d} 490}$, from the satellite-derived $\mathrm{Chl} a^{\mathrm{C}}$ (Morel and Maritorena, 2001); (2) the total attenuation coefficient, $K_{\mathrm{d}, \mathrm{PAR}}$, from $K_{\mathrm{d} 490}$ (Rochford et al., 2001); (3) finally, $Z_{\mathrm{e}}$ was retrieved from $K_{\mathrm{d} \text {, PAR }}$, using the equations of exponential decrease of light over depth.

Before computing the $\alpha$ and $\beta$ parameters, fluorescence profiles were corrected for non-photochemical quenching (NPQ). Although NPQ represents a serious issue for the fluorescence calibration (Cullen and Lewis, 1995), methods exist to evaluate, and if possible correct, the NPQ impact on the $\mathrm{Chl} a^{\mathrm{C}}$ to fluorescence ratio (Sackmann et al., 2008; Xing et al., 2012). The most complex approaches (i.e. Sackmann et al., 2008; Behrenfeld and Boss, 2006) provided fluorescence corrections on the basis of (1) other proxies for phytoplankton (i.e. optical backscattering) or (2) night light fluorescence profiles, which are not affected by NPQ. Here, we applied the method of Xing et al. (2012), which only requires mixed layer depth as input parameters to provide an NPQ correction. This method consists in extrapolating up to the surface the highest fluorescence value encountered within the mixed layer, identified after a smoothing of the profile (median filter) to reduce the noise in fluorescence data. Although this method is less sophisticated than other approaches, its large range of applicability (i.e. only mixed layer depth is required as auxiliary parameter) better matches with the rationale of our approach, which is to develop a robust method to merge satellite and fluorescence profiles. Additionally, the use of the whole $1.5 Z_{\mathrm{e}}$ layer instead of only surface records to correct fluorescence allows for a minimization of the error that would be induced by a wrong NPQ parameterization. To assess the relevance of the Xing et al. (2012) NPQ correction in the present merging method, we used the 776 pairings of matchup points located in mixed layer for the three data sets tested, obtaining a median ratio of re-adjusted fluorescence to HPLC data of 0.93, if the Xing et al. (2012) NPQ correction was previously applied and 0.78 if it was not. A Student test to compare re-adjusted fluorescence with HPLC ratios in the two conditions (i.e. with and without quenching correction) reveals that the positive effect of the Xing et al. (2012) NPQ correction is significant ( $\mathrm{p}$-value $<0.01$ ).

The coefficient $\beta$ was evaluated under the hypothesis that $\mathrm{Chl} a^{\mathrm{C}}$ was equal to zero in deep waters:

$\beta=$ average $(\operatorname{FLUO}(z))$, for $z>Z_{\text {threshold }}$

where $z$ is the depth in meters and $Z_{\text {threshold }}$ is a depth below, where the $\mathrm{Chl} a^{\mathrm{C}}$ was considered null. Here, we assumed that $Z_{\text {threshold }}=300 \mathrm{~m}$ for stratified water columns, and $Z_{\text {threshold }}=Z_{\mathrm{m}}+100 \mathrm{~m}$ for mixed water columns.

The $\alpha$ parameter for each fluorescence profile was, subsequently, determined thanks to ocean colour satellite measurements. First, using Eq. (2) and the coefficients of Uitz et al. (2006), the near-surface $\mathrm{Chl} a^{\mathrm{C}}$, measured by satellite sensor, was related to the integrated $\mathrm{Chl} a$ content over $1.5 Z_{\mathrm{e}}$, $\langle\text { chl }\rangle_{1.5 Z_{\mathrm{e}}}$ (Morel and Berthon, 1989; Uitz et al., 2006). Then, the fluorescence profile, corrected for NPQ effect, was adjusted so that $\langle\mathrm{chl}\rangle_{1.5 Z_{\mathrm{e}}}$, computed from Uitz et al. (2006) coefficients (see Table 4 in Uitz et al., 2006), and the integrated Chl $a$, measured by fluorescence, coincide. $\alpha$ was accordingly computed as followed:

$\alpha=\frac{\left\langle\operatorname{chl}_{1.5 Z_{\mathrm{e}}}\right\rangle}{\int_{0}^{1.5 Z_{\mathrm{e}}}(\operatorname{FLOU}(z)-\beta) \mathrm{d} z}$.

Note that we used integrated content over $1.5 Z_{\mathrm{e}}$, because it is recognized that important $\mathrm{Chl} a^{\mathrm{C}}$ is often present below the euphotic layer (Uitz et al., 2006).

The estimation of the parameters $\alpha$ and $\beta$ was carried out for each available fluorescence profile of the three stations, and, using Eq. (1), ocean colour/fluorescence merged profiles were finally obtained (thereafter "satellite-corrected" profiles).

\subsection{Statistics used to assess method performances}

To evaluate the method, various statistics were computed on couples of concomitant $\mathrm{Chl} a^{\mathrm{C}}$ derived from both "satellitecorrected" profiles and HPLC estimations, the last being considered as the "true" value. The two series of $\mathrm{Chl} a^{\mathrm{C}}$ estimations (i.e. "satellite-corrected" and HPLC) were matched according to the station, the sampling day and the depth. All couples of data with an HPLC-derived $\mathrm{Chl} a^{\mathrm{C}}$ greater than $0.01 \mathrm{mg} \mathrm{m}^{-3}$ were used for validation. Points located below the $1.5 Z_{\mathrm{e}}$ layer represent $18 \%$ of the validation data set.

The median value of ratio "satellite-corrected" to HPLC $\mathrm{Chl} a^{\mathrm{C}}$ estimations points to the overall bias. The semiinterquartile range (SIQR) provides insight on the spreading of data and it is defined as

$\mathrm{SIQR}=\frac{Q_{3}-Q_{1}}{2}$

where $Q_{1}$ is the 25 th percentile and $Q_{3}$ is the 75 th percentile of each series of "satellite-corrected" to HPLC ratio.

The median percent difference (MPD) was calculated to measure how accurately the $\mathrm{Chl} a^{\mathrm{C}}$ values of the "satellitecorrected" profiles agree with HPLC measurements. It is defined as the median of the individual absolute percent differences (PD), computed as

$\mathrm{PD}_{i}=100 \frac{\left|X_{i}-Y_{i}\right|}{Y_{i}}$

where $Y_{i}$ is the $\mathrm{Chl} a^{\mathrm{C}}$ measured with HPLC of the $i$-th validation point and $X_{i}$ is the corresponding "satellite-corrected" value. The determination coefficients $\left(r^{2}\right)$ of type I linear regression between "satellite-corrected" and HPLC estimations were also evaluated. 


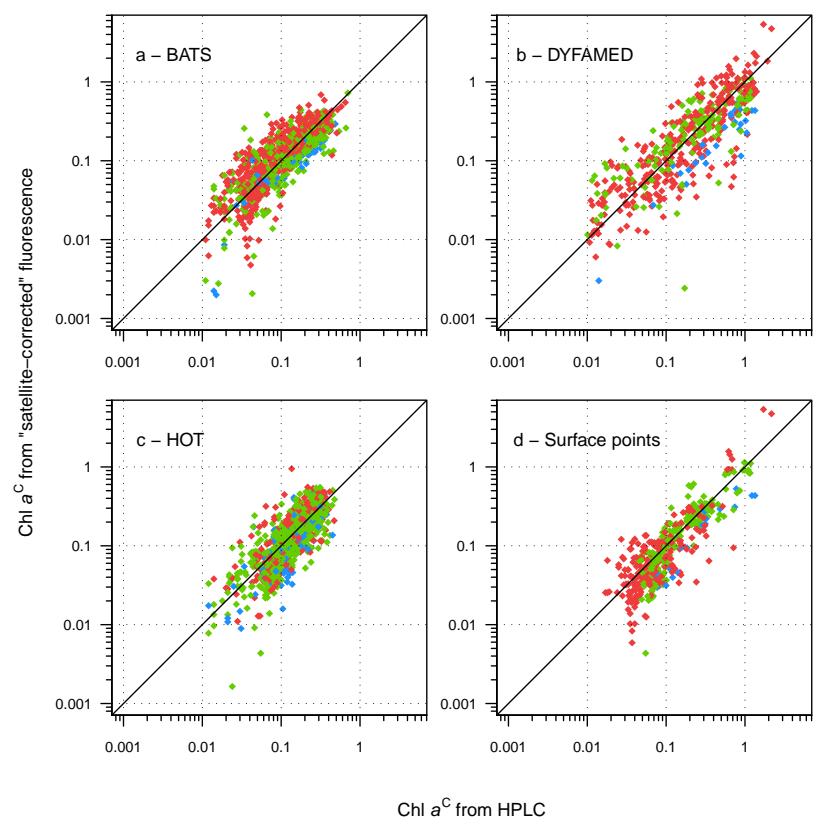

Fig. 1. Scatter plots of "satellite-corrected" $\mathrm{Chl} a^{\mathrm{C}}$ as a function of concomitant HPLC Chl $a^{\mathrm{C}}$, in $\mathrm{mg} \mathrm{m}^{-3}$. Colours characterize the error of satellite in the estimation of near surface $\mathrm{Chl} a^{\mathrm{C}}$ : overestimation exceeding $35 \%$ (red), underestimation exceeding $35 \%$ (blue) and error inferior to $\pm 35 \%$ (green). Only surface points above $20 \mathrm{~m}$ depth are displayed in (d).

\section{Results}

\subsection{Method performances}

The four terms (i.e. median "satellite-corrected" to HPLC ratio, SIQR, MPD and $r^{2}$ ) described in Sect. 3.3 were calculated for complete data sets of 2591 pairings of concurrent "satellite-corrected" with HPLC Chl $a^{\mathrm{C}}$ (491 for DYFAMED, 987 for BATS and 1113 for HOT). Because of the log-normal distribution of $\mathrm{Chl} a^{\mathrm{C}}$, values were $\log$ transformed (Campbell, 1995) prior to statistical analysis, except for the PD calculation.

Statistics and scatter plots are shown in Table 3 and Fig. 1, for each station. Figure 2 shows some examples of the initial fluorescence profiles, with their corresponding "satellitecorrected" and HPLC profiles. In Fig. 2, the satellite surface $\mathrm{Chl} a^{\mathrm{C}}$ used for merging is also depicted, as well as the "HPLC-calibrated" profiles, computed by adapting the initial fluorescence profiles to the simultaneously available discrete HPLC observations (following the method of Morel and Maritorena, 2001).

The scattering of data for the three stations is relatively homogenous for values higher than $0.05 \mathrm{mg} \mathrm{m}^{-3}$ along the $1: 1$ line for each station (Fig. 1a to c) and also for surface data ( $<20 \mathrm{~m}$, Fig. 1d), suggesting that the NPQ-correction applied here was globally efficient. The present merging method does not appear biased, as median values of the "satellite-
Table 3. Comparison of "satellite-corrected" $\mathrm{Chl}{ }^{\mathrm{C}}$ with concomitant HPLC values. The median "satellite-corrected" to HPLC $\mathrm{Chl} a^{\mathrm{C}}$ ratio, the semi-interquartile range (SIQR) measured on the previous series of ratio, the median percent difference (MPD) between "satellite-corrected" and HPLC data, as well as determination coefficient $\left(r^{2}\right)$ of the regression performed between "satellitecorrected" and HPLC data points are reported. $\mathrm{N}$ indicates the number of couples of data points available. ${ }^{*}$ refers to the variables that were calculated on log-transformed data.

\begin{tabular}{lrrrrr}
\hline & Median ratio* & SIQR $^{*}$ & MPD (\%) & $r^{2 *}$ & $N$ \\
\hline total & 1.02 & 0.17 & 31.4 & 0.68 & 2591 \\
DYFAMED & 0.95 & 0.30 & 41.2 & 0.70 & 491 \\
BATS & 1.02 & 0.15 & 29.3 & 0.67 & 987 \\
HOT & 1.04 & 0.16 & 29.4 & 0.63 & 1113 \\
\hline
\end{tabular}

corrected" to HPLC ratio are within $5 \%$ of a unit (Table 3 ). An important scatter, especially at the DYFAMED station, is, however, observed with SIQR, ranging from 0.15 to 0.30 . The MPD ranges from $29 \%$ for stations BATS and HOT to $41 \%$ for DYFAMED, with an overall median value of $31 \%$. Determination coefficients range from 0.63 for HOT to 0.70 for DYFAMED station. Not surprisingly, $r^{2}$ is higher when large ranges of $\mathrm{Chl} a^{\mathrm{C}}$ are observed (i.e. DYFAMED). From performances statistics, the DYFAMED station appears likely different from BATS and HOTS, which showed similar performances. An explication of this difference could be ascribed to the phytoplankton variability, which at DYFAMED is characterized by a marked seasonality, determining a large phytoplankton biodiversity (Marty et al., 2002). Additionally, a strong interannual variability is observed at DYFAMED, with irregular succession of blooming and nonblooming years (Bosc et al., 2004). All the above could induce a higher variability of the $\mathrm{Chl} a^{\mathrm{C}}$ to fluorescence ratio, which likely influences the performances of our approach.

The impact of the error of satellite observations on the "satellite-corrected" profiles is different for the three test stations analyzed (Table 4). At DYFAMED and BATS, the error of the "satellite-corrected" profiles (when compared with HPLC estimations) is largest when the difference between satellite and HPLC surface values is greater than $\pm 35 \%$ (Table 4 ; the $35 \%$ threshold value has been used, because it is the accepted averaged error of the satellite chlorophyll, McClain, 2009; Moore et al., 2009). Conversely, at the HOT station, the final error appears to be hardly affected by the accuracy of the satellite observations.

A comparison of the vertically integrated $\mathrm{Chl} a^{\mathrm{C}}$ was also performed (Fig. 3). Chl $a^{\mathrm{C}}$ of both "satellite-corrected" and "HPLC-calibrated" profiles was integrated over $200 \mathrm{~m}$ depth, which generally corresponds to the deepest HPLC observation. Moreover, at $200 \mathrm{~m}$ depth, $\mathrm{Chl} a^{\mathrm{C}}$ is in most cases considered to be close to zero. For the integrated $\mathrm{Chl} a^{\mathrm{C}}$, the median of "satellite-corrected" to "HPLC-calibrated" ratio is 1.02 , SIQR is 0.23 and median error is $21 \%$. Determination 

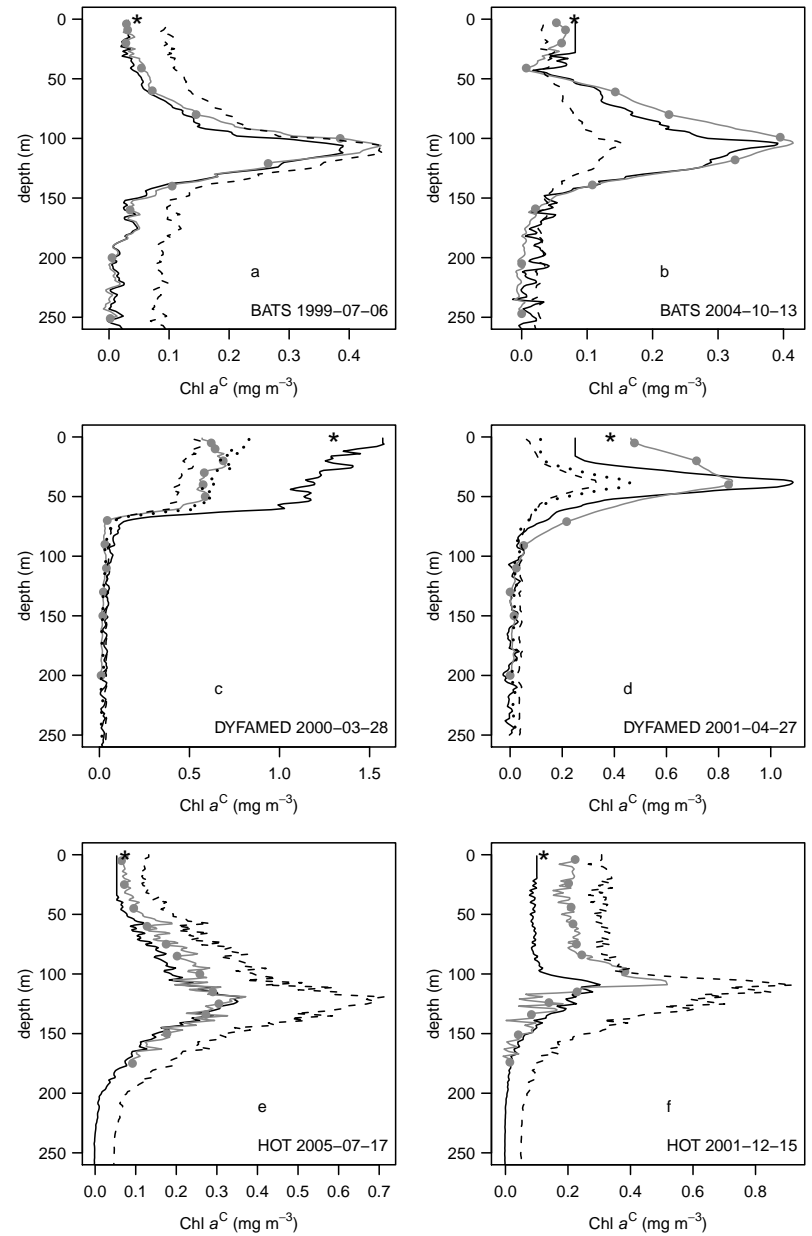

Fig. 2. Examples of "satellite-corrected" profiles (black solid line), "HPLC-calibrated" profiles (grey solid line), factory-calibrated fluorescence profiles (black dashed line) and, only for DYFAMED examples, "Boss-calibrated" profiles (black dotted lines). As a complement, HPLC data points are indicated by grey circles and satellite surface $\mathrm{Chl} a^{\mathrm{C}}$ by black stars.

coefficient in the regression model only reaches $55 \%$, indicating a relatively weak coherence between the data sets, which is particularly evident for low values. Again, satellite accuracy does impact the final result. Underestimation (overestimation) of the satellite surface $\mathrm{Chl} a^{\mathrm{C}}$ directly results in an underestimation (overestimation) of the integrated content of the "satellite-corrected" profiles. Nevertheless, the impact is less relevant than expected: of the 129 profiles with an error on satellite $\mathrm{Chl} a^{\mathrm{C}}$ higher than $35 \%$, more than half (82 profiles) showed integrated chlorophyll contents close to their corresponding HPLC-calibrated profiles (error less than $35 \%)$.

Finally, we compared the euphotic depths calculated from the "satellite-corrected" and from the "HPLC-calibrated" profiles, following the method of Morel and Berthon (1989) but with the parameterisation of Morel and Maritorena

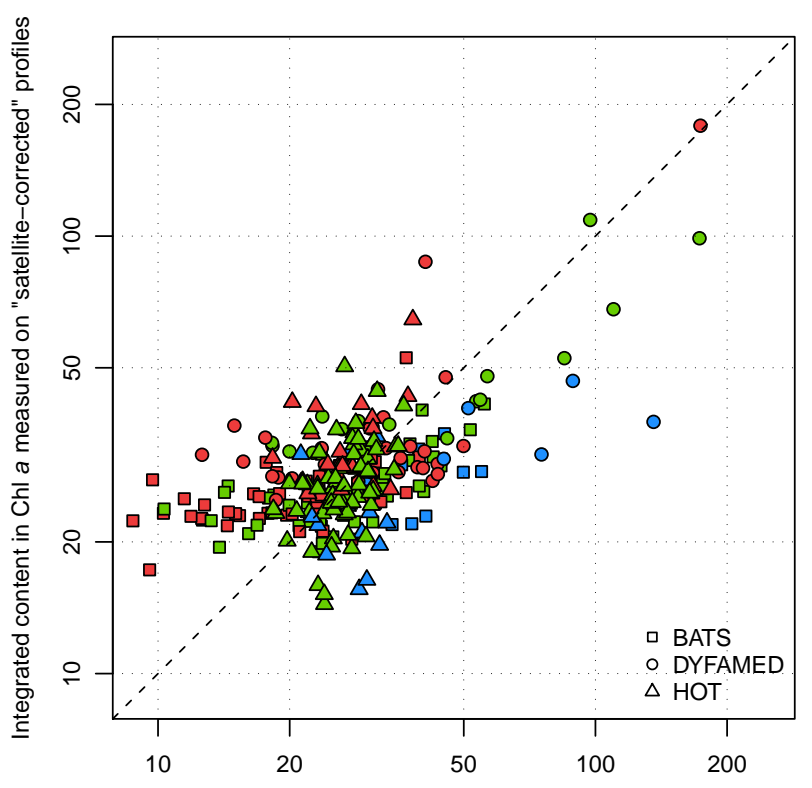

Integrated content in Chl a measured on "HPLC-calibrated" profiles

Fig. 3. Scatter plot of integrated Chl $a$ content over $200 \mathrm{~m}$ computed on "satellite-corrected" profiles, as a function of integrated Chl $a$ content computed on "HPLC-calibrated" profiles. Both Chl $a$ contents are expressed in $\mathrm{mg} \mathrm{m}^{-2}$. Similarly to Fig. 1 , colour code refers to the error of satellite in the estimation of near-surface Chl $a^{\mathrm{C}}$.

Table 4. Impact of the satellite $\mathrm{Chl} a^{\mathrm{C}}$ accuracy on the error of final corrected profiles. The satellite error was measured with the relative percent difference (rpd) between satellite extracted Chl $a^{\mathrm{C}}$ and near surface $\mathrm{Chl} a^{\mathrm{C}}$ derived from HPLC profiles. The accuracy of the merging method was assessed with the median absolute percent difference (MPD) between "satellite-corrected" and HPLC data points.

\begin{tabular}{lrr|rr|rr|r}
\hline Satellite error & \multicolumn{2}{c|}{$\mathrm{rpd}<-35$} & \multicolumn{2}{|c|}{$-35<\mathrm{rpd}<35$} & $\mathrm{rpd}>35$ & Total \\
\cline { 2 - 8 } & MPD & $N$ & MPD & $N$ & MPD & $N$ & MPD \\
\hline DYFAMED & 60.5 & 27 & 36.9 & 161 & 40.4 & 303 & 41.2 \\
BATS & 32.4 & 72 & 24.4 & 455 & 35.8 & 460 & 29.3 \\
HOT & 32.1 & 140 & 28.6 & 715 & 29.3 & 258 & 29.4 \\
\hline
\end{tabular}

(2001, Fig. 4). Note that the euphotic depth is an important parameter of our approach, since it was used to evaluate the layer of integration in Eq. (4) and to establish whether the water column is stratified or mixed. The points are uniformly scattered around the 1:1 line. Similarly to the analysis of integrated $\mathrm{Chl} a^{\mathrm{C}}$, it appears that the satellite error, determined by comparison with concomitant surface HPLC, tends to affect the estimation of $Z_{\mathrm{e}}$ in "satellite-corrected" profiles. However, the correlation between "satellite-corrected" and "HPLC-calibrated" $Z_{\mathrm{e}}$ is satisfying (median ratio of "satellite-corrected" to "HPLC-calibrated" $=0.97$, SIQR $=$ $0.09, \mathrm{MPD}=9.5 \%, r^{2}=0.64$ ). 


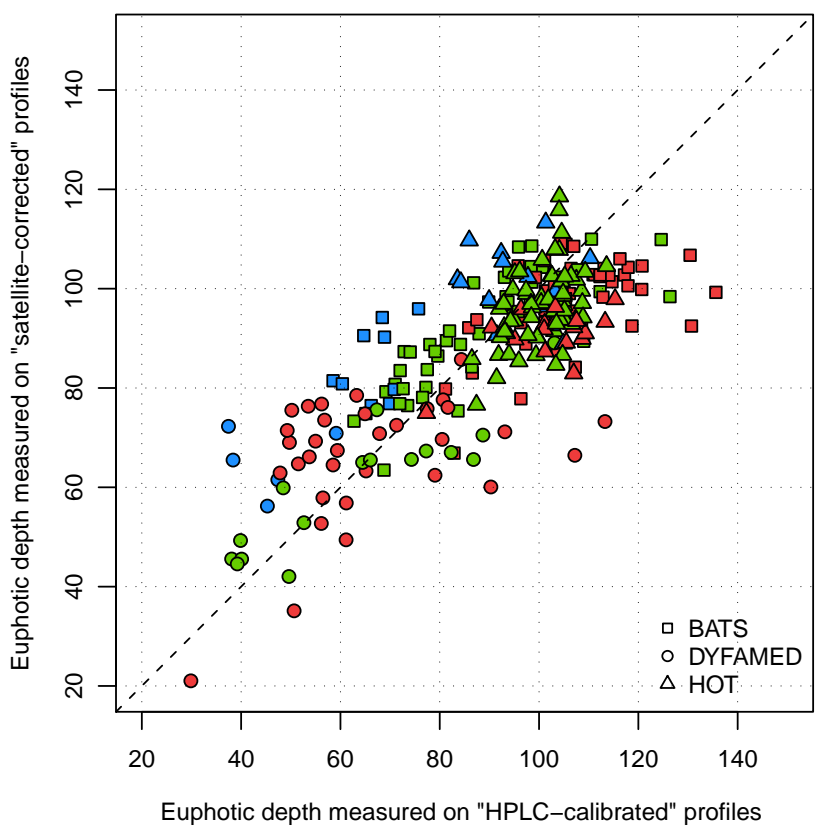

Fig. 4. Scatter plot of the euphotic depth computed on "satellitecorrected" profiles as a function of the euphotic depth computed on "HPLC-calibrated" profiles using the algorithm described by Morel and Berthon (1989). Both euphotic depths are expressed in meters (m). Similarly to Fig. 1, colour code refers to the error of satellite in the estimation of near-surface $\mathrm{Chl} a^{\mathrm{C}}$.

\subsection{Comparison with the method proposed by Boss et al. (2008)}

Even though differences exist, our approach is close to the Boss et al. (2008) fluorescence correction method. Both methods use a satellite reference, except that the Boss et al. (2008) approach uses only surface data to compare with remote sensing and was developed to be applied to a set of fluorescence profiles measured by a unique instrument (i.e. profiling float), free of instrumental drift. To verify the performances of both approaches, we selected a subset of data from the DYFAMED data set, in order to be as close as possible to the terms of applicability of the Boss et al. (2008) method (i.e. data obtained by a unique instrument). The DYFAMED subset of profiles was obtained by a single fluorometer from 2000 to 2002 . To verify that there was no instrumental drift during this period, the deep fluorescence values have been checked (i.e. deep values between a standard deviation from the long-term mean). The resulting subset of DYFAMED data comprises 47 fluorescence profiles, 24 of which were associated with a concomitant HPLC profile.

By definition, the coefficients $\alpha$ and $\beta$ in the Boss et al. (2008) approach (called $\alpha_{B}$ and $\beta_{B}$ hereafter) were considered constant. Using the 47 profiles available, $\beta_{B}$ was computed using the median value of the $\beta$ coefficients computed with our method. The $\alpha_{B}$ coefficient was calculated as the type II regression slope of a regression analysis per-
Table 5. Comparison, on a subset of DYFAMED data, of "satellitecorrected" and "Boss-calibrated" $\mathrm{Chl} a^{\mathrm{C}}$ with concomitant HPLC values. See the caption of Table 3 for details about parameters.

\begin{tabular}{lrrrrr}
\hline & Median ratio* & SIQR* & MPD (\%) & $r^{2 *}$ & $N$ \\
\hline Boss et al. (2008) & 0.97 & 0.23 & 42.1 & 0.86 & 213 \\
Present paper & 0.92 & 0.28 & 41.9 & 0.78 & 213 \\
\hline
\end{tabular}

formed between surface satellite $\mathrm{Chl} a^{\mathrm{C}}$ and the corresponding surface values of fluorescence profiles. Note, however, that the satellite $\mathrm{Chl} a^{\mathrm{C}}$ product that we used has different spatial $(9 \mathrm{~km}$ instead of $1 \mathrm{~km}$ in Boss et al., 2008) and temporal (8-day instead of 1-day) resolutions.

The comparison of "satellite-corrected" and "Bosscalibrated" profiles (i.e. fluorescence profiles calibrated with the Boss et al., 2008, method) with concomitant HPLC $\mathrm{Chl} a^{\mathrm{C}}$ estimations (Table 5, 213 validation points) indicates that the performance indexes of both methods are equivalent (MPD $=41.9 \%$ with the present method and $42.1 \%$ with the Boss et al., 2008, method). Dispersion is slightly reduced with the Boss et al. (2008) method compared with the present merging method ( $\mathrm{SIQR}=0.23$ against 0.28 with our method and $r^{2}=0.86$ against 0.78 ). Also, our merging method seems more sensitive to the accuracy of satellite data (see example in Fig. 2c and d).

\subsection{Examples of application}

\subsubsection{Chlorophyll $a$ climatology}

The utilisation of the large data set of fluorescence profiles, once properly adjusted, should strongly improve the existing climatologies.

1. We linearly interpolated the HPLC discrete profiles in the vertical to generate nearly continuous profiles at $1 \mathrm{~m}$ resolution. Twelve monthly HPLC average values were then calculated over standard depths, defined for each station by considering the most recurrently sampled depths. At each standard depth, monthly climatological means were also computed by averaging, for a given month, the $\mathrm{Chl} a^{\mathrm{C}}$ extracted from the "satellitecorrected" profiles. The resulting mean values were finally compared with the HPLC-derived estimations (Fig. 5 and Table 6). Resulting statistics are generally improved (see Table 6): SIQR is 0.11 (instead of 0.16 for the single profile application); MPD is $22 \%$ (instead of $31 \%$ ) and $r^{2}$ is 0.82 (instead of 0.67). HPLC to "satellite-corrected" data spreading is also reduced, with most of the points concentrated around the 1:1 line. However, as also observed for the single profile comparison (Fig. 1), dispersion increases for concentrations lower than $0.05 \mathrm{mg} \mathrm{m}^{-3}$. 
Table 6. Comparison between "satellite-corrected" $\mathrm{Chl} a \mathrm{C}$ and concomitant HPLC values after having applied a monthly average filter. See the caption of Table 3 for details about parameters.

\begin{tabular}{lrrrrr}
\hline & Median ratio* & SIQR* & MPD $(\%)$ & $r^{2 *}$ & $N$ \\
\hline total & 1.03 & 0.11 & 21.6 & 0.82 & 432 \\
DYFAMED & 1.03 & 0.30 & 33.9 & 0.80 & 144 \\
BATS & 1.02 & 0.08 & 16.3 & 0.85 & 144 \\
HOT & 1.04 & 0.10 & 18.4 & 0.80 & 144 \\
\hline
\end{tabular}

2. The utilisation of "satellite-corrected" profiles led us to envisage new types of climatologies that could better reproduce the vertical distribution of $\mathrm{Chl} a^{\mathrm{C}}$. A new procedure is proposed here (see Appendix A for computation details). Briefly, the procedure tends to identify, in all available $\mathrm{Chl} a^{\mathrm{C}}$ profiles, relevant features of the profile, such as the DCM depth, and averages them to reconstruct a climatological profile, which depicts the main characteristics of typical $\mathrm{Chl} a^{\mathrm{C}}$ profiles. Such a procedure is, consequently, based on the a-priori knowledge of the typical shapes of $\mathrm{Chl} a^{\mathrm{C}}$ profiles and does not allow the merging of two $\mathrm{Chl} a^{\mathrm{C}}$ profiles that have different shapes. Here, we distinguished Chl $a^{\mathrm{C}}$ profiles marked by a DCM and attributed to stratified water columns to homogeneous profiles characterising the mixed water columns (Mignot et al., 2011). As an example, this procedure was applied to the BATS "satellite-corrected" profiles (Fig. 6). Comparing the new climatology with a climatology based on HPLC discrete samples (Fig. 6), we observed that the marked seasonality of the $\mathrm{Chl} a^{\mathrm{C}}$ field, characteristic of the region (Steinberg et al., 2001), is well reproduced in both climatologies. When most of Chl $a^{\mathrm{C}}$ profiles have a stratified shape (i.e. April to December), the two climatologies agree at surface and below the DCM. However, the HPLC-based climatology shows shallower and weaker DCMs than those observed in the so-called fluorescence-based climatology, particularly in spring. When the mixed situation dominates (i.e. January to March), the fluorescence-based climatological profiles are constant in surface layers $(0-100 \mathrm{~m})$, whereas HPLC-based climatological profiles display a sub-surface maximum.

\subsubsection{Autonomous platforms}

The merging method was then applied to calibrate NPQcorrected fluorescence data obtained from a PROVBIO, an Argo-like profiling float equipped with a fluorometer (Xing et al., 2011). The float was deployed in the Eastern Mediterranean Sea, collecting 90 profiles between 27 June 2008 and 8 November 2009. As the SeaWiFS sensor was sometimes deficient during the 2008/2009 period, satellite data extrac-

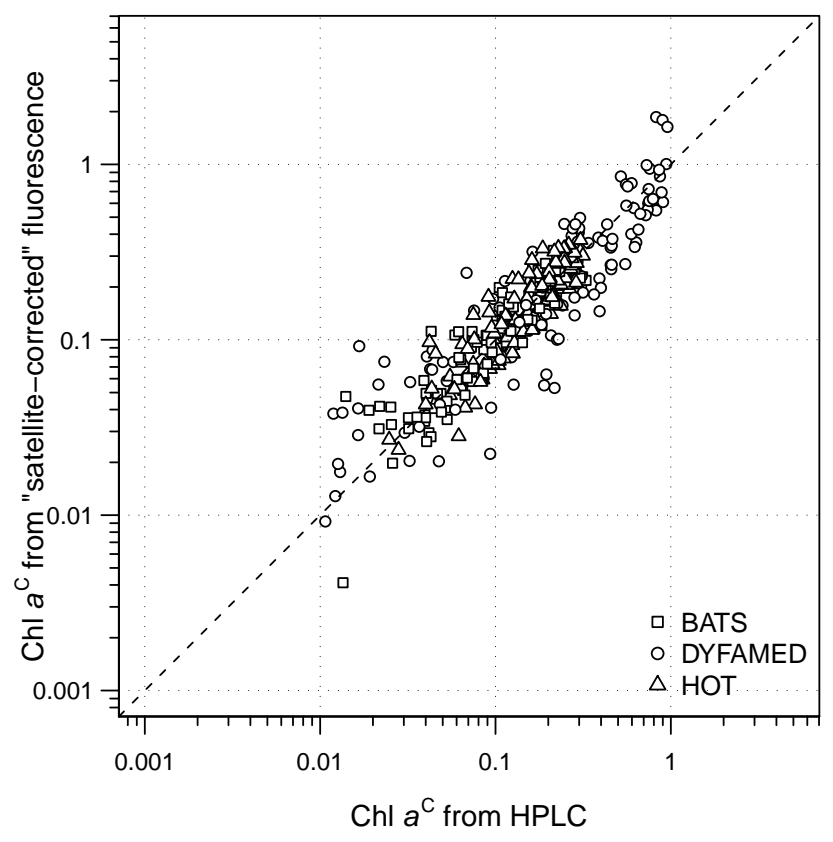

Fig. 5. Scatter plot of Chl $a^{\mathrm{C}}$ derived from "satellite-corrected" fluorescence profiles as a function of Chl $a^{\mathrm{C}}$ measured with HPLC, after having applied a monthly average filter. $\mathrm{Chl} a^{\mathrm{C}}$ is expressed in $\mathrm{mg} \mathrm{m}^{-3}$.

tion was achieved using MODIS 8-day data. The time series of "satellite-corrected" profiles is presented in Fig. 7a. A well-marked seasonal cycle, consistent with previous observations of Krom et al. (1992), is observed. This cycle presents a strong stratification of the water column in summer, characterized by a DCM between 100 and 125 $\mathrm{m}$ depth. During winter, $\mathrm{Chl} a^{\mathrm{C}}$ is quite constant throughout the mixed layer, which deepened to more than $250 \mathrm{~m}$ in February/March 2009. Chl $a^{\mathrm{C}}$ values never exceeded $0.68 \mathrm{mg} \mathrm{m}^{-3}$. The maxima are observed at the DCM (summer 2008, spring 2009), in agreement with the well-known characteristics of the Mediterranean oligotrophic areas (Moutin and Raimbault, 2002).

For the sake of comparison, the modified Boss et al. (2008) method (see Sect. 4.2) was also applied (Fig. 7b). The two series of profiles are consistent from July to September 2008, with $\mathrm{Chl} a^{\mathrm{C}}$ ranges between 0 and $0.65 \mathrm{mg} \mathrm{m}^{-3}$. Important differences are however observed for the rest of the period (from October 2008 to October 2009), when the "Bosscalibrated" Chl $a^{\mathrm{C}}$ is lower (on average $0.15 \mathrm{mg} \mathrm{m}^{-3}$ difference at DCM).

\section{Discussion}

Compared with HPLC references, "satellite-corrected" fluorescence profiles are globally unbiased, presenting an $r^{2}$ of about $67 \%$ and a median error of about $31 \%$. These errors (Figs. 1, 3 and 4, Table 4) are certainly affected by the 

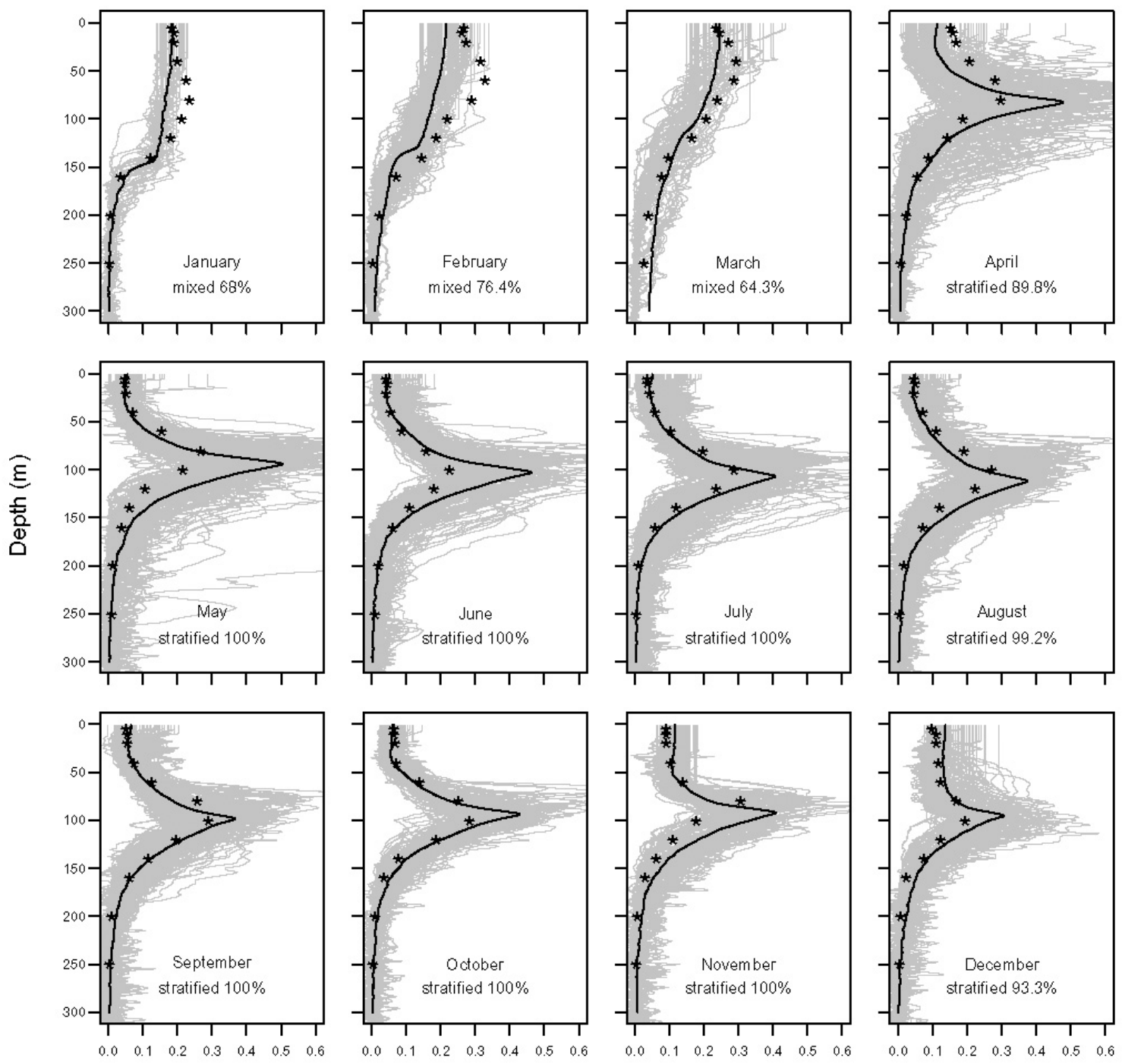

$\mathrm{Chl} a^{\mathrm{C}}\left(\mathrm{mg} \cdot \mathrm{m}^{-3}\right)$

Fig. 6. Comparison of the BATS monthly fluorescence-based Chl $a^{\mathrm{C}}$ climatology (black solid lines) to the HPLC-based climatology (black stars; see text and Appendix A for details about computation methods). For the fluorescence-based climatology, the retained shape (i.e. "stratified" or "mixed") is indicated with its percentage of occurrence, and grey lines display all the "satellite-corrected" profiles representing the dominant shape.

uncertainty of satellite $\mathrm{Chl} a^{\mathrm{C}}$ measurements. Our analysis demonstrated that when the error of satellite $\mathrm{Chl} a^{\mathrm{C}}$ is lower than $35 \%$ (i.e. the estimated averaged accuracy of ocean colour mission; McClain, 2009), our method performs better. However, several studies indicated that ocean colour $\mathrm{Chl} a^{\mathrm{C}}$ observations could have error greater than $35 \%$, in particular over certain localised areas (e.g. the Mediterranean Sea; D'Ortenzio et al., 2002, the Antarctic or the Equatorial Atlantic; Gregg and Casey, 2004). In these situations, particular attention should be dedicated to the interpretation of our "satellite-corrected" profiles.

The matchup procedure used to associate a satellite observation with a fluorescence profile could also have an impact on the final $\mathrm{Chl} a^{\mathrm{C}}$ profile. However, a narrower matchup protocol (i.e. 1-day) does not significantly enhance the performance (Table 1); although, conversely, it does decrease the number of available satellite observations, (cloud cover limits the satellite coverage in the match up box) and, therefore, their statistical relevance.

Another potential source of error derives from the conversion of surface $\mathrm{Chl} a^{\mathrm{C}}$ into integrated $\mathrm{Chl} a$ content over the water column (Eq. (2), as obtained by regression analyses performed by Uitz et al., 2006). However, the use of vertically integrated contents to calculate the correction coefficients, i.e. Eq. (4), does not change the method performance, when compared with HPLC estimations (Table 5). 

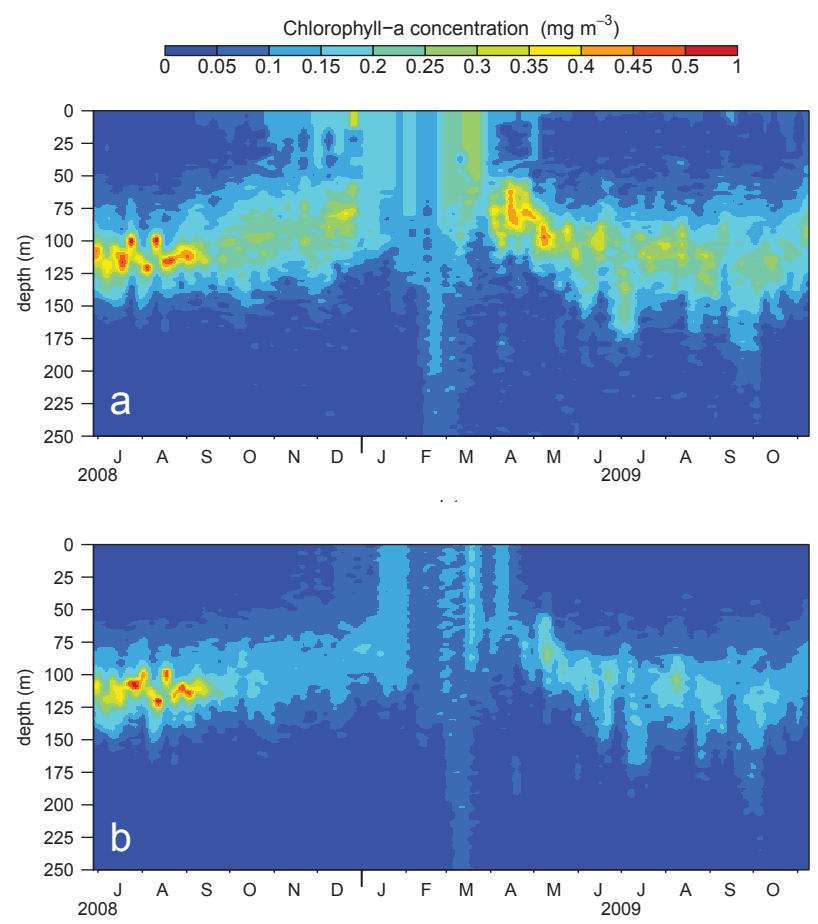

Fig. 7. Time series of Chl $a^{\mathrm{C}}$ distribution estimated with a fluorometer deployed on a profiling float in the Levantine Sea and processed with the present method (a) and with the Boss et al. (2008) method (b).

We suppose that integrating over the $1.5 Z_{\mathrm{e}}$ decreases the impact of the vertical variability of the $\mathrm{Chl} a^{\mathrm{C}} /$ fluorescence ratio on the final calculation of $\alpha$. Additionally, using integrated contents, the $\alpha$ calculation is less affected by the method of NPQ correction.

A possible alternative to Eq. (2) is the use of surface measurements, as proposed by Boss et al. (2008). In this case, however, the variability of the $\mathrm{Chl} a \mathrm{C} / f$ luorescence relationship could have a larger impact on the final profile, as a possible error in the surface data should propagate all along the water column. Moreover, for surface observations, the accuracy of the NPQ correction (i.e. surface measurements are more affected by NPQ than deep values) and of the satellite estimations is likely crucial. In our data set tests, however, these effects seem minimized (Table 5) and we suppose that this is mainly due to the statistical significance of the regression used to calculate $\alpha_{B}$ (p-value $=2 \times 10^{-7}$ for the DYFAMED subset). If the statistical relevance of the regression to calculate $\alpha_{B}$ had been low (e.g. few match-ups, important satellite errors, regional biases), even profiles having a good satellite match-up would have been erroneously re-adjusted.

The Boss et al. (2008) method therefore represents a powerful tool, and a valid alternative, to correct fluorescence profiles and to produce vertical estimations of $\mathrm{Chl} a^{\mathrm{C}}$ consistent with satellite data. Our method is merely an improvement of the Boss et al. (2008) method. The main methodologi- cal differences between the two approaches seem to have a very weak impact on the final errors (Table 5), and the two methods appear equivalent from the point of view of the error analysis. However, the Boss et al. (2008) method was specifically developed to derive an accurate estimation of $\mathrm{Chl} a^{\mathrm{C}}$ from fluorescence measurements performed by a profiling float, which was (1) equipped with a unique fluorometer, (2) spanning a three-year period only, (3) floating in a limited, although vast, ocean region (western North Atlantic). For this reason, their method was based on a unique correction factor for all the series of profiles and, to match satellite observations, they used only surface data.

Our objective has been to enhance the Boss et al. (2008) method so as to be able to process any fluorescence profile having a concurrent satellite observation (after 1997). Consequently, we decided to (1) generate a correction factor for each profile, (2) enlarge the temporal and spatial window of the satellite observations, to ensure a match-up, even in regions with low satellite coverage and (3) use $1.5 Z_{\mathrm{e}}$ integration depth instead of surface points only, to minimize the effect of the error propagation along the vertical scale in case of high vertical variability of the Chl $a^{\mathrm{C}} /$ fluorescence ratio. We are confident that, with these characteristics, our method could be widely applied (e.g. to all fluorescence profiles in the NODC database collected after 1997). Furthermore, the corrected data set of fluorescence profiles could be used to generate a satellite/fluorescence blended product of the $\mathrm{Chl} a^{\mathrm{C}}$.

The potential of this blended product is evident for the generation of a new type of climatology of $\mathrm{Chl} a^{\mathrm{C}}$. Compared with a climatology generated with only discrete samples (i.e. HPLC), the new fluorescence-based climatology exhibits some differences, mainly in the mixed layer and at the DCM (Fig. 6). The causes of these discrepancies must be ascribed to methodological issues. In particular, climatologies based on HPLC discrete points generally require interpolations on the vertical scale, which could smooth the final mean profile (see Fig. 6). Additionally, averaging mixed and stratified profiles generates atypical shapes (see winter months of the HPLC-based climatology at BATS, Fig. 6), which have no correspondence with the initial data set, but are pure artefacts of the mean procedure. In the new fluorescence-based climatology (Fig. 6), the dominant shape (i.e. stratified or mixed) appears more clearly and the proposed method to calculate the climatological profile results in marked DCM peaks, as generally expected.

The merging method proposed here has also been applied to a profiling float fluorometer, and the obtained results were compared with those derived from the method of Boss et al. (2008), which was specifically developed for profiling float data. The application of the two procedures on a single set of fluorescence profiles leads to different results (Fig. 7). At the present stage, it is impossible to definitely assess which method is closest to the truth. However, both the methods are consistent, by definition, with the concurrent 
satellite estimations. In other words, the profiling float observations could be easily merged with satellite ocean colour maps, to finally generate a unique 3-D picture of the $\mathrm{Chl} a^{\mathrm{C}}$ field. The use of this 3-D picture of Chl $a^{\mathrm{C}}$ could improve the operational simulations of oceanic ecosystems, in particular in an assimilation scheme (Brasseur et al., 2009). In this context, our method appears more promising than the Boss et al. (2008) procedure, which rather requires the utilisation of all the fluorescence profiles achieved during the whole lifetime of the float to determine correction coefficients, and thus cannot be applied in real-time.

\section{Conclusions}

We have presented a method to merge fluorescence profiles and satellite ocean colour observations, which allows uniforming the existing $\mathrm{Chl} a^{\mathrm{C}}$ estimations derived from fluorescence observations. Fluorescence profiles, obtained from a range of fluorometers and factory calibrations and under various trophic and environmental conditions, were corrected with a unique and stable reference provided by ocean colour satellites. Consequently, for the first time, the huge data set of fluorescence profiles collected during the last $15 \mathrm{yr}$ could be inter-compared. Moreover, the corrected fluorescence profiles are consistent with satellite observations; their integration and merging with other data sources should be strongly facilitated.

The limits of the present method are essentially determined by the limits of the data sets used (i.e. fluorescence and satellite observations). If no satellite match-ups are available, a merging procedure cannot be performed. Consequently, all fluorescence profiles performed before 1997 (date of launching of the SeaWiFS sensor), as well as profiles achieved in high latitudes, cannot be merged with satellite data. Biases are also induced by the error of satellite ocean colour, which represents the first source of error of our method. However, the error estimated by comparing "satellite-corrected" fluorescence profiles with HPLC estimations is only slightly higher than the error estimated for the ocean colour satellite observations. In addition, packaging effect constitutes another limit of the method, because vertical $a^{*}$ variability was not resolved in the method. Strictly speaking, the proposed method is not a calibration procedure, which should imply a more accurate evaluation of the sensor responses. In our approach, fluorescence profiles are only corrected and readjusted to be consistent with satellite estimations. Nevertheless, the resulting corrected profiles show lower errors than the initial fluorescence profiles, when compared with HPLC estimations.

Although we accept that the merging method presented here cannot substitute, in terms of accuracy, the calibrations derived from laboratory analyses to determine $\mathrm{Chl} a^{\mathrm{C}}$, it does, nevertheless, present specific advantages that could be particularly adapted for specific applications. We presented here two examples: the improvement of the $\mathrm{Chl} a^{\mathrm{C}}$ climatology and the treatment of fluorescence data measured by a profiling float. These two applications will probably converge in the future: at the present time, the only climatology available (Conkright et al., 2002) is based on discrete bottle data and suffers from (1) a critical lack of data and (2) a really poor vertical resolution. Integrating existing "satellite-corrected" fluorescence profiles in Chl $a^{\mathrm{C}}$ climatologies should help in filling these gaps. Moreover, the high flux of fluorescence data provided by the increased number of profiling floats will definitively reinforce our capacity for describing, climatologically and in real time, the $\mathrm{Chl} a^{\mathrm{C}}$ field. In this framework, our approach could be considered one of the steps for a future quality control system for a network of profiling floats. However, it should be used only when other methods fail or are inapplicable, to prevent any redundant information or circular exercise if a validation of satellite ocean colour products is attempted with the profiling floats observations.

\section{Appendix A}

\section{Procedure to generate the new, fluorescence-based, $\mathrm{Chl} a^{\mathrm{C}}$ climatology}

1. All the fluorescence profiles available for a given month were sorted into two categories: stratified and mixed with respect to the $Z_{\mathrm{m}} / Z_{\mathrm{e}}$ ratio. If $Z_{\mathrm{m}} / Z_{\mathrm{e}}>1$, the profile is associated with the mixed category; otherwise, it is associated with the stratified category.

2. On one hand, the climatological profile representing the stratified category was computed as follows: (a) on each stratified profile, the DCM was identified as the absolute maximum on the vertical scale; (b) the profile depths were normalized by the depth of the DCM; (c) all the depth-normalized profiles were then averaged, for each unity of the dimensionless vertical scale; (d) the resulting mean profile was finally reconverted to a metric scale, using a multiplicative factor obtained by averaging the DCM depths of all the profiles. On the other hand, the climatological profile corresponding to the mixed category was computed in a similar way as the climatological stratified profile except that the DCM depth used for normalization was replaced by the mixed layer depth.

3. Finally, only the climatological profile corresponding to the more frequent category (stratified or mixed) was retained to represent the monthly climatological Chl $a$ distribution. 
Acknowledgements. The authors would like to thank all the staff of the DYFAMED observation service and of the BATS and HOT programs for the periodic measurements of oceanographic variables, and for the free distribution of data online. The US NASA space agency is thanked for the easy access to SeaWiFS and MODIS data. The authors are also grateful to Louis Prieur and Alexandre Mignot, for constructive comments and suggestions, to Joséphine Ras for reviewing the manuscript and to Emmanuel Boss (Univ. of Maine) who kindly provided details about his method. This paper is a contribution to the PABIM (Plateformes Autonomes Biogéochimiques: Instrumentation et Mesures) project funded by the Groupe Mission Mercator Coriolis (GMMC), to the PABO (Plateformes Autonomes and Biogéochimie Océanique) project funded by Agence Nationale de la Recherche (ANR) and to the remOcean (REMotely sensed biogeochemical cycles in the OCEAN) project, funded by the Grant agreement No. 246777.

Edited by: E. Boss

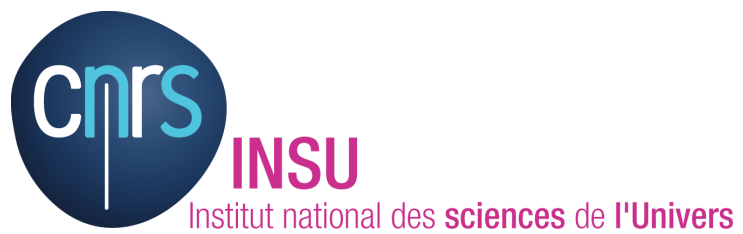

The publication of this article is financed by CNRS-INSU.

\section{References}

Althuis, I. A., Gieskes, W. W. C., Villerius, L., and Colijn, F.: Interpretation of fluorometric chlorophyll registrations with Algal pigment analysis along a ferry transect in the Southern North Sea, Neth. J. Sea Res., 33, 37-46, 1994.

Bailey, S. and Werdell, P.: A multi-sensor approach for the on-orbit validation of ocean color satellite data products, Remote Sens. Environ., 102, 12-23, doi:10.1016/j.rse.2006.01.015, 2006.

Behrenfeld, M. J. and Boss, E.: Beam attenuation and chlorophyll concentration as alternative optical indices of phytoplankton biomass, J. Mar. Res., 64, 431-451, doi:10.1357/002224006778189563, 2006.

Bosc, E., Bricaud, A., and Antoine, D.: Seasonal and interannual variability in algal biomass and primary production in the Mediterranean Sea, as derived from 4 years of SeaWiFS observations, Global Biogeochem. Cy., 18, GB1005, doi:10.1029/2003GB002034, 2004.

Boss, E., Collier, R., Larson, G., Fennel, K., and Pegau, W.: Measurements of spectral optical properties and their relation to biogeochemical variables and processes in Crater Lake, Crater Lake National Park, OR, Hydrobiologia, 574, 149-159, doi:10.1007/s10750-006-2609-3, 2007.

Boss, E., Swift, D., Taylor, L., Brickley, P., Zaneveld, R., Riser, S., Perry, M., and Strutton, P.: Observations of pigment and particle distributions in the western North Atlantic from an autonomous float and ocean color satellite, Limnol. Oceanogr., 53, 21122122, doi:10.4319/lo.2008.53.5_part_2.2112, 2008.

Boyer, T., Antonov, J., Baranova, O., Garcia, H., Johnson, D., Locarnini, R., Mishonov, A., O’Brien, T., Seidov, D., Smolyar, I., and Zweng, M.: World Ocean Database 2009, edited by: Levitus, S., NOAA Atlas NESDIS 66U.S. Gov. Printing Office, Wash., DC, 216 pp., DVDs, 2009.

de Boyer Montegut, C., Madec, G., Fischer, A., Lazar, A., and Iudicone, D.: Mixed layer depth over the global ocean: An examination of profile data and a profile-based climatology, J. Geophy. Res.-Oceans, 109, C12003, doi:10.1029/2004JC002378, 2004.

Brasseur, P., Gruber, N., Barciela, R., Brander, K., Doron, M., El Moussaoui, A., Hobday, A., Huret, M., Kremeur, A., Lehodey, P., Matear, R., Moulin, C., Muturgudde, R., Senina, I., and Svendsen, E.: Integrating Biogeochemistry and Ecology Into Ocean Data Assimilation Systems, Oceanography, 22, 206-215, 2009.

Campbell, J. W.: The lognormal distribution as a model for biooptical variability in the sea, J. Geophys. Res., 100, 1323713254, doi:199510.1029/95JC00458, 1995.

Cetinic, I., Toro-Farmer, G., Ragan, M., Oberg, C., and Jones, B.: Calibration procedure for Slocum glider deployed optical instruments, Optics Express, 17, 15420-15430, 2009.

Claustre, H., Morel, A., Babin, M., Cailliau, C., Marie, D., Marty, J.-C., Tailliez, D. and Vaulot, D.: Variability in particle attenuation and chlorophyll fluorescence in the tropical Pacific: scales, patterns, and biogeochemical implications, J. Geophys. Res., 104, 3401-3422, 1999.

Claustre, H., Antoine, D., Boehme, L., Boss, E., D’Ortenzio, F., Fanton D'Andon, O., Guinet, C., Gruber, N., Handegard, N. O., Hood, M., Johnson, K., Lampitt, R., LeTraon, P.-Y., Lequéré, C., Lewis, M., Perry, M.-J., Platt, T., Roemmich, D., Testor, P., Sathyendranath, S., Send, U., and Yoder, J.: Guidelines Towards an Integrated Ocean Observation System for Ecosystems and Biogeochemical Cycles, in: Proceedings of OceanObs'09: Sustained Ocean Observations and Information for Society (Vol. 2), Venice, Italy, 21-25 September 2009, edited by: Hall, J., Harrison, D. E., and Stammer, D., ESA Publication WPP-306, doi:10.5270/OceanObs09.pp.14, 2010.

Cleveland, J. S. and Perry, M. J.: Quantum yield, relative specific absorption and fluorescence in nitrogen-limited Chaetoceros gracilis, Mar. Biol., 94, 489-497, 1987.

Conkright, M., O’Brien, T., Stephens, K., Locarnini, R., Garcia, H., Boyer, T., and Antonov, J.: World Ocean Atlas 2001, Volume 6: Chlorophyll, edited by: Levitus, S., NOAA Atlas NESDIS 54, US Governement Printing Office, Wash., DC, 46 pp., 2002.

Cullen, J.: The Deep Chlorophyll Maximum - Comparing Vertical Profiles of Chlorophyll-A, Can. J. Fish. Aquat. Sci., 39, 791-803, 1982.

Cullen, J. and Lewis, M.: Biological processes and optical measurements near the sea surface: some issues relevant to remote sensing, J. Geophy. Res-Oceans, 100, 13255-13266, 1995.

Davis, R. F., Moore, C. C., Zaneveld, J. R. V., and Napp, J. M.: Reducing the effects of fouling on chlorophyll estimates derived from long-term deployments of optical instruments, J. Geophys. Res., 102, 5851-5855, doi:199710.1029/96JC02430, 1997.

D’Ortenzio, F., Marullo, S., Ragni, M., Ribera d'Alcalà, M., and Santoleri, R.: Validation of empirical SeaWiFS algorithms for chlorophyll-a retrieval in the Mediterranean Sea: A case study for oligotrophic seas, Remote Sens. Environ., 82, 79-94, doi:16/S0034-4257(02)00026-3, 2002.

D’Ortenzio, F., Iudicone, D., Montegut, C., Testor, P., Antoine, D., Marullo, S., Santoleri, R., and Madec, G.: Seasonal variability of the mixed layer depth in the Mediterranean Sea as 
derived from in situ profiles, Geophys. Res. Lett., 32, L12605, doi:10.1029/2005GL022463, 2005.

D’Ortenzio, F., Thierry, V., Eldin, G., Claustre, H., Testor, P., Coatanoan, C., Tedetti, M., Guinet, C., Poteau, A., Prieur, L., Lefevre, D., Bourin, F., Carval, T., Goutx, M., Garçon, V., Thouron, D., Lacombe, M., Lherminier, P., Loisel, H., Mortier, L., and Antoine, D.: White Book on Oceanic Autonomous Platforms for Biogeochemical Studies: Instrumentation and Measure (PABIM) version 1.3, available at: http://www.obs-vlfr.fr/ OAO/file/PABIM_white_book_version1.3.pdf (last access: 2012), 2010.

Falkowski, P. and Kiefer, D. A.: Chlorophyll a fluorescence in phytoplankton: relationship to photosynthesis and biomass, J. Plankton Res., 7, 715-731, 1985.

Feldman, G., Kuring, N., Ng, C., Esaias, W., McClain, C., Elrod, J., Maynard, N., and Endres, D.: Ocean color: Availability of the global data set, Eos Trans. AGU, 70, 634, doi:10.1029/89EO00184, 1989.

Gieskes, W. W. and Kraay, G. W.: Unknown Chlorophyll $a$ derivatives in the North Sea and the Tropical Atlantic ocean revealed by HPLC analysis, Limnol. Oceanogr., 28, 757-766, 1983.

Gregg, W. W. and Conkright, M.: Global seasonal climatologies of ocean chlorophyll: Blending in situ and satellite data for the Coastal Zone Color Scanner era, J. Geophy. Res.-Oceans, 106, 2499-2515, 2001.

Gregg, W. W. and Casey, N. W.: Global and regional evaluation of the SeaWiFS chlorophyll data set, Remote Sens. Environ., 93, 463-479, doi:10.1016/j.rse.2003.12.012, 2004.

Holm-Hansen, O., Lorenzen, C. J., Holmes, R. W., and Strickland, J. D. H.: Fluorometric Determination of Chlorophyll, Ices J. Mar. Sci., 30, 3-15, doi:10.1093/icesjms/30.1.3, 1965.

Hooker, S. B., Van Heukelem, L., Thomas, C. S., Claustre, H., Ras, J., Schülter, L., Clementson, L., Van der Linde, L., Eker-Develi, E., Berthon J.-F., Barlow, R., Sessions, H., Ismail, H., and Perl, J.: The third SeaWiFS HPLC Analysis Round-Robin Experiment (SeaHARRE-3), NASA technical Memorandum 2009-215849, Greenbelt: NASA Goddard Space Flight Center, 2009.

Karl, D. M. and Lukas, R.: The Hawaii Ocean Time-series (HOT) program: Background, rationale and field implementation, DeepSea Res. Pt. II, 43, 129-156, doi:16/0967-0645(96)00005-7, 1996.

Kiefer, D. A.: Fluorescence properties of natural phytoplankton populations, Mar. Biol., 22, 263-269, 1973.

Kolber, Z. and Falkowski, P. G.: Use of Active Fluorescence to Estimate Phytoplankton Photosynthesis in Situ, Limnol. Oceanogr., 38, 1646-1665, 1993.

Krom, M., Brenner, S., Kress, N., Neori, A., and Gorgon, L.: Nutrient Dynamics and New Production in a Warm-Core Eddy from the Eastern Mediterranean-Sea, Deep-Sea Res., 39, 467-480, 1992.

Loftus, M. and Seliger, H.: Some Limitation of the In Vivo Fluorescence Technique, Chesapeake Science, 16, 79-92, 1975.

Lorenzen, C. J.: A method for the continuous measurement of in vivo chlorophyll concentration, Deep-Sea Res., 13, 223-227, 1966.

Lorenzen, C. J.: Determination of Chlorophyll and Pheo-Pigments: Spectrophotometric Equations, Limnol. Oceanogr., 12, 343-346, 1967.
Mantoura, R. F. C. and Llewellyn, C. A.: The rapid determination of algal chlorophyll and carotenoid pigments and their breakdown products in natural waters by reverse-phase highperformance liquid chromatography, Anal. Chim. Acta, 151, 297-314, doi:10.1016/S0003-2670(00)80092-6, 1983.

Marty, J.-C., Chiavérini, J., Pizay, M.-D. and Avril, B.: Seasonal and interannual dynamics of nutrients and phytoplankton pigments in the western Mediterranean Sea at the DYFAMED timeseries station (1991-1999), Deep-Sea Res. Pt. II, 49, 1965-1985, doi:16/S0967-0645(02)00022-X, 2002.

McClain, C. R.: A Decade of Satellite Ocean Color Observations, Annual Rev. Mar. Sci., 1, 19-42, doi:10.1146/annurev.marine.010908.163650, 2009.

McClain, C., Cleave, M., Feldman, G., Gregg, W., Hooker, S., and Kuring, N.: Science quality SeaWiFS data for global biosphere research, Sea Technol., 39, 10-16, 1998.

Michaels, A. F. and Knap, A. H.: Overview of the U.S. JGOFS Bermuda Atlantic Time-series Study and the Hydrostation S program, Deep-Sea Res. Pt. II, 43, 157-198, doi:16/09670645(96)00004-5, 1996.

Mignot, A., Claustre, H., D’Ortenzio, F., Xing, X., Poteau, A., and Ras, J.: From the shape of the vertical profile of in vivo fluorescence to Chlorophyll- $a$ concentration, Biogeosciences, 8, 23912406, doi:10.5194/bg-8-2391-2011, 2011.

Moore, T. S., Campbell, J. W., and Dowell, M. D.: A class-based approach to characterizing and mapping the uncertainty of the MODIS ocean chlorophyll product, Remote Sens. Environ., 113, 2424-2430, doi:10.1016/j.rse.2009.07.016, 2009.

Morel, A.: Optical modeling of the upper ocean in relation to its biogenous matter content (case-I waters), J. Geophy. ResOceans, 93, 10749-10768, 1988.

Morel, A. and Berthon, J.: Surface pigments, algal biomass profiles, and potential production of the euphotic Layer - Relationships reinvestigated in view of remote-sensing applications, Limnol. Oceanogr., 34, 1545-1562, 1989.

Morel, A. and Bricaud, A.: Theoretical results concerning light absorption in a discrete medium, and application to specific absorption of phytoplankton, Deep-Sea Res., 28, 1375-1393, doi:10.1016/0198-0149(81)90039-X, 1981.

Morel, A. and Maritorena, S.: Bio-optical properties of oceanic waters: A reappraisal, J. Geophy. Res.-Oceans, 106, 7163-7180, 2001.

Moutin, T. and Raimbault, P.: Primary production, carbon export and nutrients availability in western and eastern Mediterranean Sea in early summer 1996 (MINOS cruise), J. Marine Syst., 3334, 273-288, doi:10.1016/S0924-7963(02)00062-3, 2002.

Müller, P., Li, X.-P., and Niyogi, K. K.: Non-Photochemical Quenching. A Response to Excess Light Energy, Plant Physiol., 125, 1558-1566, doi:10.1104/pp.125.4.1558, 2001.

Ras, J., Claustre, H., and Uitz, J.: Spatial variability of phytoplankton pigment distributions in the Subtropical South Pacific Ocean: comparison between in situ and predicted data, Biogeosciences, 5, 353-369, doi:10.5194/bg-5-353-2008, 2008.

Rochford, P., Kara, A., Wallcraft, A. and Arnone, R.: Importance of solar subsurface heating in ocean general circulation models, J. Geophy. Res.-Oceans, 106, 30923-30938, 2001.

Sackmann, B. S., Perry, M. J., and Eriksen, C. C.: Seaglider observations of variability in daytime fluorescence quenching of chlorophyll- $a$ in Northeastern Pacific coastal waters, Biogeo- 
sciences Discuss., 5, 2839-2865, doi:10.5194/bgd-5-2839-2008, 2008.

Sharples, J., Moore, C. M., Rippeth, T. P., Holligan, P. M., Hydes, D. J., Fisher, N. R., and Simpson, J. H.: Phytoplankton Distribution and Survival in the Thermocline, Limnol. Oceanogr., 46, 486496, 2001.

Steinberg, D., Carlson, C., Bates, N., Johnson, R., Michaels, A. and Knap, A.: Overview of the US JGOFS Bermuda Atlantic Timeseries Study (BATS): a decade-scale look at ocean biology and biogeochemistry, Deep-Sea Res. Pt. II, 48, 1405-1447, 2001.

Strass, V.: On the calibration of large-scale fluorometric chlorophyll measurements from towed undulating vehicles, Deep-Sea Res., 37, 525-540, doi:10.1016/0198-0149(90)90023-O, 1990.

Strickland, J. D. H.: Production of organic matter in primary stages of the marine food chain, in Chemical Oceanography, edited by: Riley, J. P. and Skirrow, G., Academic Press, London, 477-610, 1965.
Strickland, J. D. H.: Continuous measurement of in vivo chlorophyll; a precautionary note, Deep-Sea Res., 15, 225-227, 1968.

Uitz, J., Claustre, H., Morel, A., and Hooker, S.: Vertical distribution of phytoplankton communities in open ocean: An assessment based on surface chlorophyll, J. Geophy. Res.-Oceans, 111, C08005, doi:10.1029/2005JC003207, 2006.

Xing, X., Morel, A., Claustre, H., Antoine, D., D’Ortenzio, F., Poteau, A. and Mignot, A.: Combined processing and mutual interpretation of radiometry and fluorimetry from autonomous profiling Bio-Argo floats: Chlorophyll $a$ retrieval, J. Geophys. Res., 116, C06020, doi:10.1029/2010JC006899, 2011.

Xing, X., Claustre, H., Blain, S., D’Ortenzio, F., Antoine, D., Ras, J., and Guinet, C.: Quenching correction for in vivo chlorophyll fluorescence measured by instrumented elephant seals in the Kerguelen region (Southern Ocean), Limnol. Oceanogr.-Meth., in press, 2012. 